\title{
Operational tools in the Basque Country (south-eastern Bay of Biscay) for water quality management within harbours
}

\author{
A. Del Campo, L. Ferrer, A. Fontán, M. González, J. Mader, \\ A. Rubio \& Ad. Uriarte \\ Marine Research Division, AZTI-Tecnalia, Spain
}

\begin{abstract}
In this contribution, a pre-operational local oceanic system, which combines data acquisition with numerical modelling in the two main harbours of the Basque Country, Bilbao and Pasaia, is described. The analysis of wind and current measurements showed the adequacy of the data acquisition system to provide open boundary conditions to solve the hydrodynamics in the internal part of the harbour domains. The use of the Finite Element hydrodynamic model, TRIMODENA, combined with a Lagrangian Particle Tracking Model (LPTM), offers a viable method to simulate the spatio-temporal evolution of pollutant dispersion for water quality management in an operational way. Some applications of the present modelling system are shown.
\end{abstract}

Keywords: Bay of Biscay, operational oceanography, numerical modelling, harbour, management, pollution.

\section{Introduction}

Oceanography has progressed rapidly over the past three decades. This has been driven by the need to develop new technologies, issues related to navigation, climate change, marine ecosystems and water quality management. The latest advances in oceanography provide a new challenge to the scientific community: Operational Oceanography, defined by Fischer et al. [1] as the activity of systematic and long-term routine measurements of seas, oceans and atmosphere, and their rapid interpretation and dissemination.

Recently, many public administrations have decided to provide financial support for a wide range of projects in Operational Oceanography, such as: 
EuroGOOS (European co-operation on the Global Observing System) and ECOOP (European COastal-shelf sea OPerational observing and forecasting system) in Europe and ESEOO (Establishment of a Spanish Operational Oceanography System) in Spain. In the Basque Country, two projects facilitate the development of local operational systems: ITSASEUS (supported by the Basque Government) and LOREA (Litoral, Océano y Riberas de EuskadiAquitania, funded by the European INTERREG-IVA project). All these projects are focused on providing useful tools, for the atmosphere and ocean, through operational systems which combine data acquisition with numerical modelling. The developed tools will enable the creation of products for the monitoring of several unusual phenomena as well as routine activities such as: atmospheric pollution, storms and surge warnings, high waves, sediment transport, oil spills, river plumes, aerial and maritime traffic, design of marine structures, or coastal water quality.

Within the framework of the ITSASEUS and LOREA projects, the Basque pre-operational oceano-meteorological system is made up of different subsystems that will be highly co-ordinated to provide different resolutions on global, regional and local scales. Preliminary results by Ferrer et al. [2] have shown the capacity of the applied models to predict oceano-meteorological phenomena at regional scales. In this paper, the capabilities of the present preoperational local oceanic sub-system to forecast currents and pollutant dispersion, within the two main harbours of the Basque Country, are described.

\section{Study areas}

The Basque country is located in the innermost part of the Bay of Biscay, in the Cantabrian Sea, included as part of the North Atlantic Ocean (Figure 1). In the western part of the Basque Country, Bilbao harbour is located at the mouth of the Nervión estuary (Figure 1). This estuary is the largest in this region, with a surface area of about $20 \mathrm{~km}^{2}$, an average depth of $30 \mathrm{~m}$ and a mean annual river flow of about $36 \mathrm{~m}^{3} \cdot \mathrm{s}^{-1}$. The harbour has been growing progressively from the inner part of the Nervión River to the outer estuarine and open sea areas, becoming one of the most important harbours in Europe. In the eastern part of the Basque Country, Pasaia harbour is located within the Oiartzun estuary (Figure 1). This estuary is surrounded by mountains and relatively small with a surface area of about $1 \mathrm{~km}^{2}$, an average depth of $10 \mathrm{~m}$ and a mean annual river flow of about $5 \mathrm{~m}^{2} \cdot \mathrm{s}^{-1}$. The Pasaia harbour is, from a commercial point of view, the second most important harbour in the Basque Country.

\section{Operational observation and modelling tools}

\subsection{Real-time oceano-meteorological data and bathymetric information}

The available oceano-meteorological data, including location, instrument type, record length and sampling rate, is presented in Table 1. 

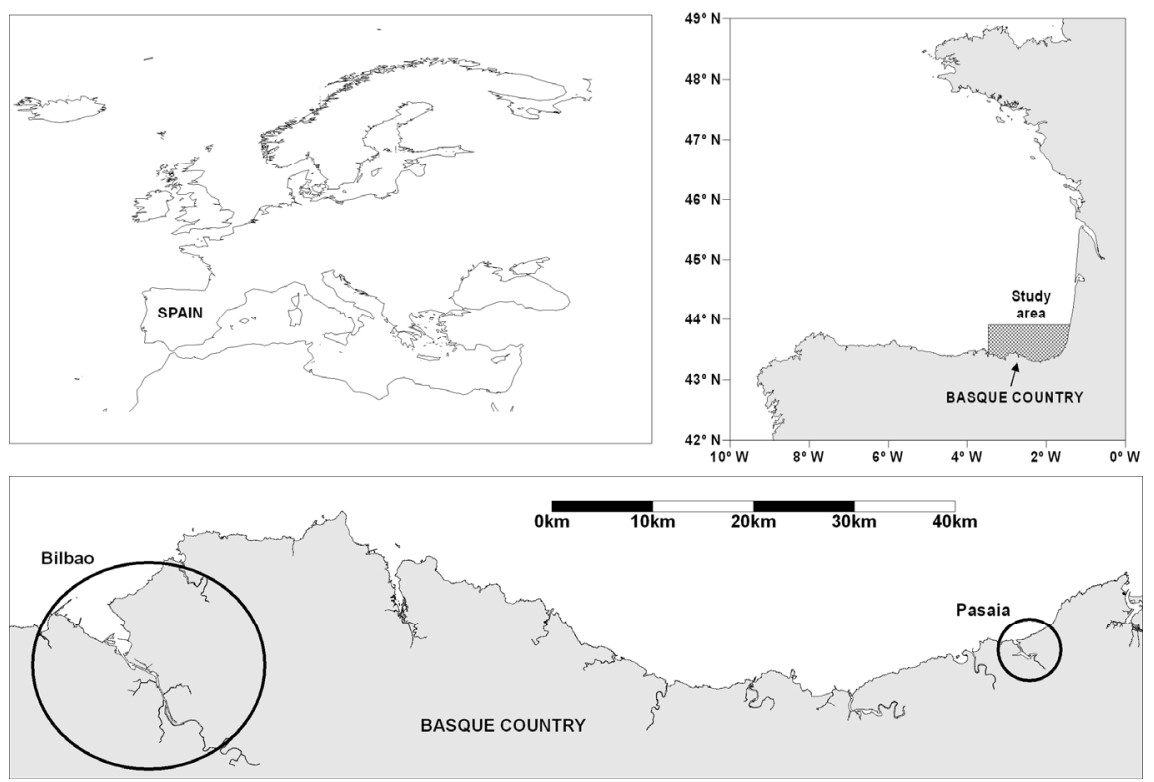

Figure 1: Location of Bilbao and Pasaia harbours in the Basque coast.

Table 1: Description of presented oceano-meteorological stations (EOM), including its location, record length and sampling rate.

\begin{tabular}{|c|c|c|c|c|c|c|}
\hline $\begin{array}{l}\text { Station } \\
\text { reference }\end{array}$ & Location & $\begin{array}{l}\text { Instrument } \\
\text { type }\end{array}$ & $\begin{array}{l}\text { Station elevation } \\
\text { / water depth } \\
\text { (above and } \\
\text { below sea level) } \\
\text { (m) }\end{array}$ & $\begin{array}{c}\text { Mean } \\
\text { depth } \\
\text { below } \\
\text { surface }(\mathrm{m})\end{array}$ & $\begin{array}{l}\text { Start } \\
\text { date }\end{array}$ & $\begin{array}{l}\text { Sampling } \\
\text { rate (min) }\end{array}$ \\
\hline $\begin{array}{c}\text { EOM } \\
\text { PASAIA }\end{array}$ & $\begin{array}{c}43^{\circ} 20.3^{\prime} \mathrm{N} \\
1^{\circ} 55.5^{\prime} \mathrm{W}\end{array}$ & $\begin{array}{l}\text { AANDERAA } \\
\text { DCM-12 Doppler, } \\
\text { Tide gauge and }\end{array}$ & $16 / 24$ & $\begin{array}{c}0-4-8- \\
12-16- \\
20\end{array}$ & $\begin{array}{l}\text { Aug. } \\
2001\end{array}$ & 10 \\
\hline $\begin{array}{c}\text { EOM } \\
\text { BILBAO }\end{array}$ & $\begin{array}{l}43^{\circ} 22.7^{\prime} \mathrm{N} \\
3^{\circ} 04.9^{\prime} \mathrm{W}\end{array}$ & $\begin{array}{c}\text { Automatic } \\
\text { Weather Station }\end{array}$ & $22 / 30$ & $\begin{array}{c}0-4-9- \\
13-17- \\
22\end{array}$ & $\begin{array}{l}\text { Aug. } \\
2003\end{array}$ & 10 \\
\hline
\end{tabular}

Oceanic data (currents, sea surface variations, temperature and turbidity) and atmospheric variables (temperature, wind, pressure and solar radiation) are collected at the stations every ten minutes. At these stations, information on current is provided by an upward-looking ADCP, which measures the current speed and direction at 6 depths within the water column. Atmospheric measurements are collected at 16 and $22 \mathrm{~m}$ above mean sea level at the Pasaia and Bilbao stations, respectively.

In both harbour domains, $1 \mathrm{~m}$ resolution seafloor Digital Terrain Models from high resolution multibeam system (Seabat 7125) are used for bathymetric information. 


\subsection{The hydrodynamic modelling system}

The modelling system applied to simulate the water circulation within the described harbour domains is the 3D hydrodynamic model TRIMODENA. This software consists of two hydrodynamic modules: ECADIS [3], which calculates density and wind-induced currents; and MAREAS [4], which estimates the astronomical tidal propagation and the induced currents and water levels.

ECADIS and MAREAS solve the Shallow Water Equations (SWE), by means of the Finite Element Method (FEM) with quasi-3D approximations [5]. ECADIS processes the stationary part of the SWE, using the macro-element technique and the penalty function applied by Fortin and Fortin [6]. The model MAREAS solves the tidal propagation equations, expressed as a sum of a finite series of harmonic constituents [7], using a horizontal Q1/P0 discretization and vertical spectra decomposition. The spatial extent defined for Bilbao harbour extends from $43^{\circ}$ $14^{\prime}$ to $43^{\circ} 25^{\prime} \mathrm{N}$ and from $3^{\circ} 09^{\prime}$ to $2^{\circ} 51^{\prime} \mathrm{W}$, with a mean horizontal resolution of $20.4 \mathrm{~m}$. The grid for Pasaia harbour extends from $43^{\circ} 20^{\prime}$ to $43^{\circ} 23^{\prime} \mathrm{N}$ and from $1^{\circ} 58^{\prime}$ to $\left.1^{\circ} 52^{\prime} \mathrm{W}\right)$.

\subsection{Lagrangian particle-tracking model}

A Lagrangian Particle-Tracking Model, LPTM, is used to forecast the pollutant dispersion within the harbours of Bilbao and Pasaia. This model is fed by the output of the TRIMODENA hydrodynamic model simulations. The current fields computed on the TRIMODENA grid are used by the LPTM, to estimate the particle velocities where the pollutants are located in each time step. LPTM uses random turbulent velocity terms to parameterise unresolved sub-grid phenomena along both, the horizontal and vertical axes. The method used for the dispersion estimation is based upon the $4^{\text {th }}$ order Runge-Kutta scheme.

\section{Description of oceano-meteorological conditions}

The oceano-meteorological conditions over the study areas are described by means of the available wind and oceanic data from Pasaia and Bilbao stations (Table 1). These also are compared with the model results.

Wind frequency distribution analyses were performed on data acquired from January 2004 to December 2006. At the Bilbao station, the wind direction field showed a seasonal pattern, in agreement with the results of Medina [8] and Usabiaga et al. [9]. In accordance with observations of these authors for the Basque coast, the dominant winds are from the south in winter and autumn and from the north in spring and summer. Wind data at the Pasaia station showed a different pattern from that observed at the Bilbao station; the former is dominated by southerlies throughout the year. This observation suggests that seasonal southerlies are reinforced by land breezes at the Pasaia station, due to their channelling along Pasaia Bay as pointed out by Fontán et al. [10]. Land effects are important in coastal areas of the Basque Country, especially at Pasaia harbour due to its complex topography. 
In order to estimate the contribution of wind to the variability of the surface current at Pasaia station, the squared coherence spectra for wind and sea surface current components, from January 2004 to December 2006, were calculated (Figure 2). The contribution of wind, to surface current fluctuations, occurs over a wide range of frequencies, ranging from: terdiurnal, semidiurnal and diurnal land-sea breezes; to periods of several days, representing the passage of cyclones/anticyclones; to lower frequencies near fortnightly periods, representing changes in the prevailing weather conditions; and, finally, to seasonal variability as pointed out by Fontan et al. [10]. Close agreement was observed between sea surface and sub-surface currents and wind measurements, indicating that water circulation is governed mainly by wind forcing fluctuations, over a wide range of meteorological frequencies. This is in accordance with observations of Fontán et al. [10].

Surface current data measured at the Pasaia station throughout 2008 and surface currents computed by the hydrodynamic model TRIMODENA were compared (Figure 3). For surface current computation within the model, the input wind data were those measurements observed at the Pasaia station. Overall, a high level of agreement is observed between computed and observed surface currents; $57 \%$ of the variability in the surface current measurements is explained by model computations.

\section{Applications to water quality management}

The described tools have been used for some operational applications within the two harbour domains. One of these applications is the analysis of the extension and dilution of industrial effluent discharges in the far-field (i.e. the region where

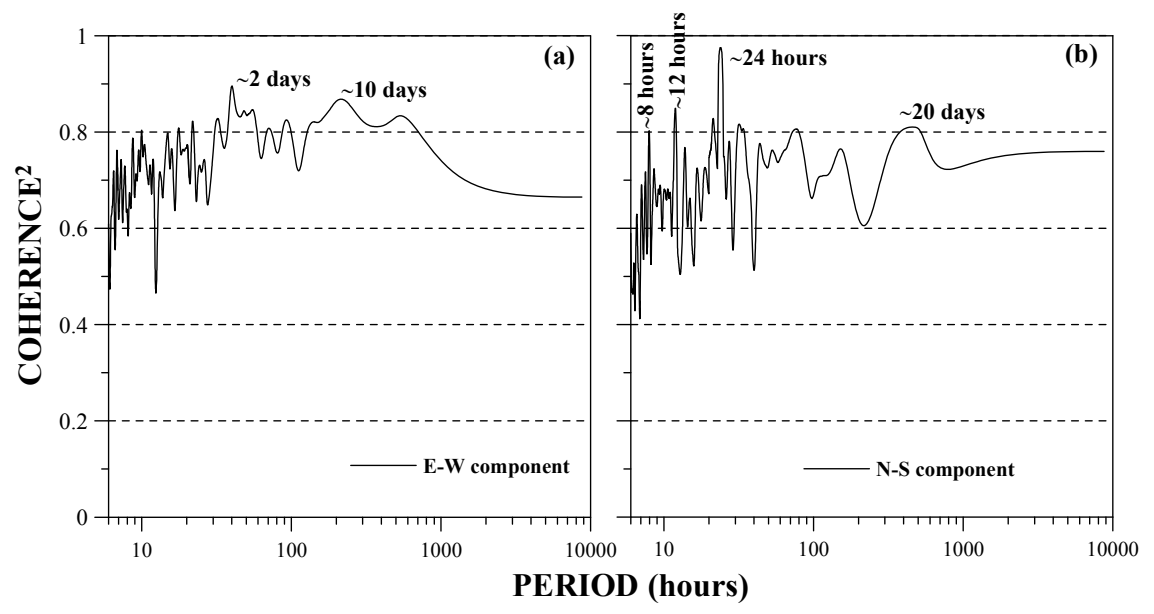

Figure 2: $\quad$ Smoothed squared coherence spectra ( $99 \%$ significance level) of current and wind components, at the Pasaia station, from January 2004 to December 2006 for: eastward (a) and northward (b) components at sea surface. 


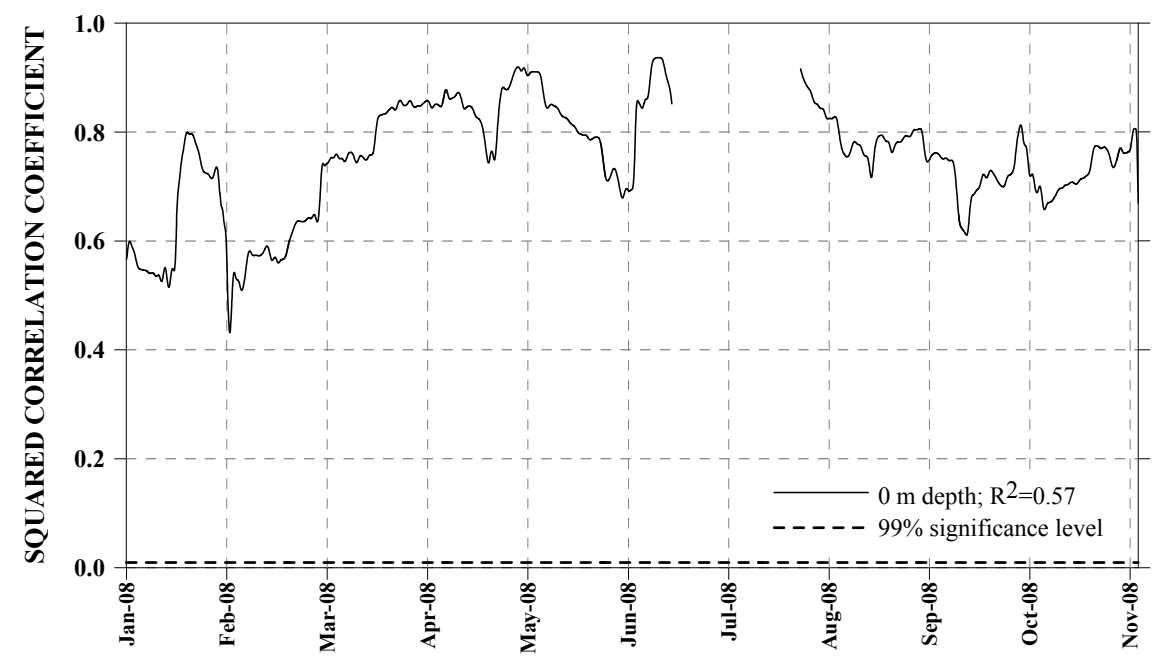

Figure 3: $\quad$ Squared correlation coefficient sequences (99\% significance level) between measured and computed surface currents at the Pasaia station in 2008. The sample size in each case is 720 hours.

the mixing is dominated by the ambient flow conditions). Historical wind data from the oceano-meteorological stations were analysed to obtain the local wind probability distributions. Each probable wind is used as an input in ECADIS to compute the local wind-induced currents. In these types of studies, the transport processes in the near-field are simulated with CORMIXI [11]. The dimensions and temperature of the effluent predicted by CORMIXI in the near-field are used to define an initial patch of particles.

Short time steps were used to compute current fields with ECADIS and MAREAS, to estimate the particle velocities used in the LPTM. In order to simulate the continuous discharge flow rate, patches of particles with the same characteristics are defined at each time step. Figure 4 shows an example of the temperature increment field of a thermal power plant discharge at the Bilbao harbour. The computation of the most probable effluent discharge extension could be used as a parameter to estimate the environmental risk of pollutant discharges within a harbour.

Other direct applications of these numerical tools, in relation to a Pollution Event Management Program, are the simulations of the fate of potential oil spills within a harbour domain. The resultant analysis of these simulations provide useful maps which enable port authority administrations plan response strategies and the resources needed for clean up operations within the Local Oil Spill Contingency Plan. An example of these maps is shown in Figure 5 where the oil fate or retention zones for each study area are represented with a line. The potential pollution points shown in these maps correspond to the locations used by the oil companies as working space on both land and at sea. 


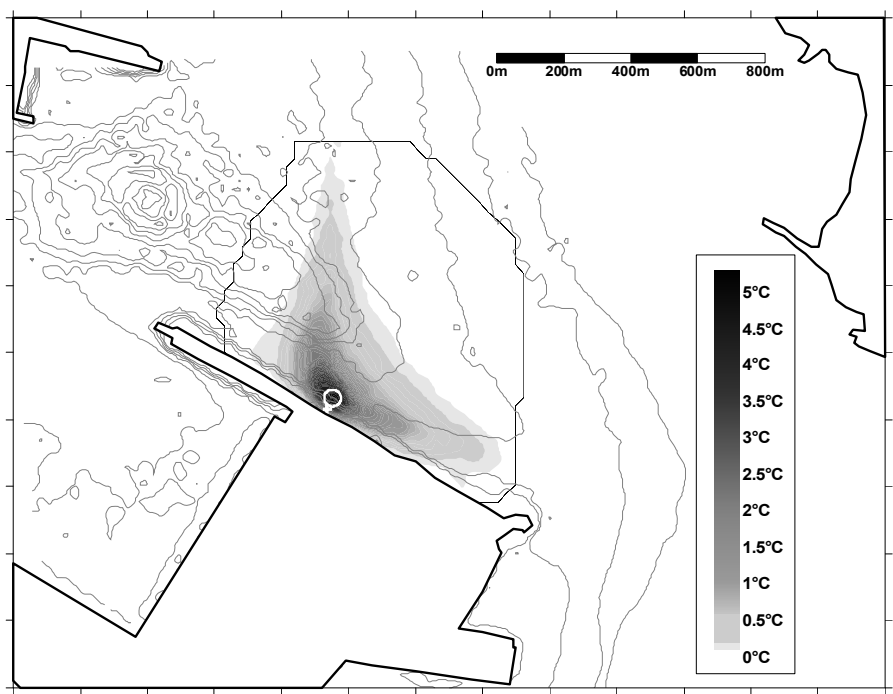

Figure 4: Thermal plume dispersion at the Bilbao harbour.

It is worthwhile to note, that the extrapolation of the prevailing winds observed by these stations, to the entire computational harbour domain may not always be appropriate, particularly for the inner part of the harbour. This may be especially valid in the case of Pasaia, where the presence of mountains almost certainly modifies the wind pattern.

At present, TRIMODENA and LPTM are being used as prediction tools, in real-time, for a rapid response to a potential oil spills in the Bilbao harbour; AZTI-Tecnalia is providing daily local 72-hour forecasts of particle trajectories to the Port Authority of Bilbao. At the moment, in the absence of a higher resolution local wind model, TRIMODENA is being forced by the forecasts obtained from the meteorological model MM5 (Fifth-Generation NCAR / Penn State Mesoscale Model).

\section{Conclusions}

The meteorological conditions at the study areas have been described by three years of wind measurements from the Pasaia and Bilbao oceano-meteorological stations. Whilst winds at the Bilbao station showed similar seasonal patterns to those described by other authors for the Basque coast, winds at the Pasaia station showed a marked influence of land-sea breezes due to their channelling along the Pasaia Bay. With respect to the marine conditions, a surface current data analysis from the Pasaia station revealed that surface water circulation is governed by wind forcing in the external area of this harbour. The clear agreement between measured and numerically simulated currents with the TRIMODENA hydrodynamic model throughout the year at the Pasaia station has shown the adequate capability of the model to predict wind-induced currents outside the 

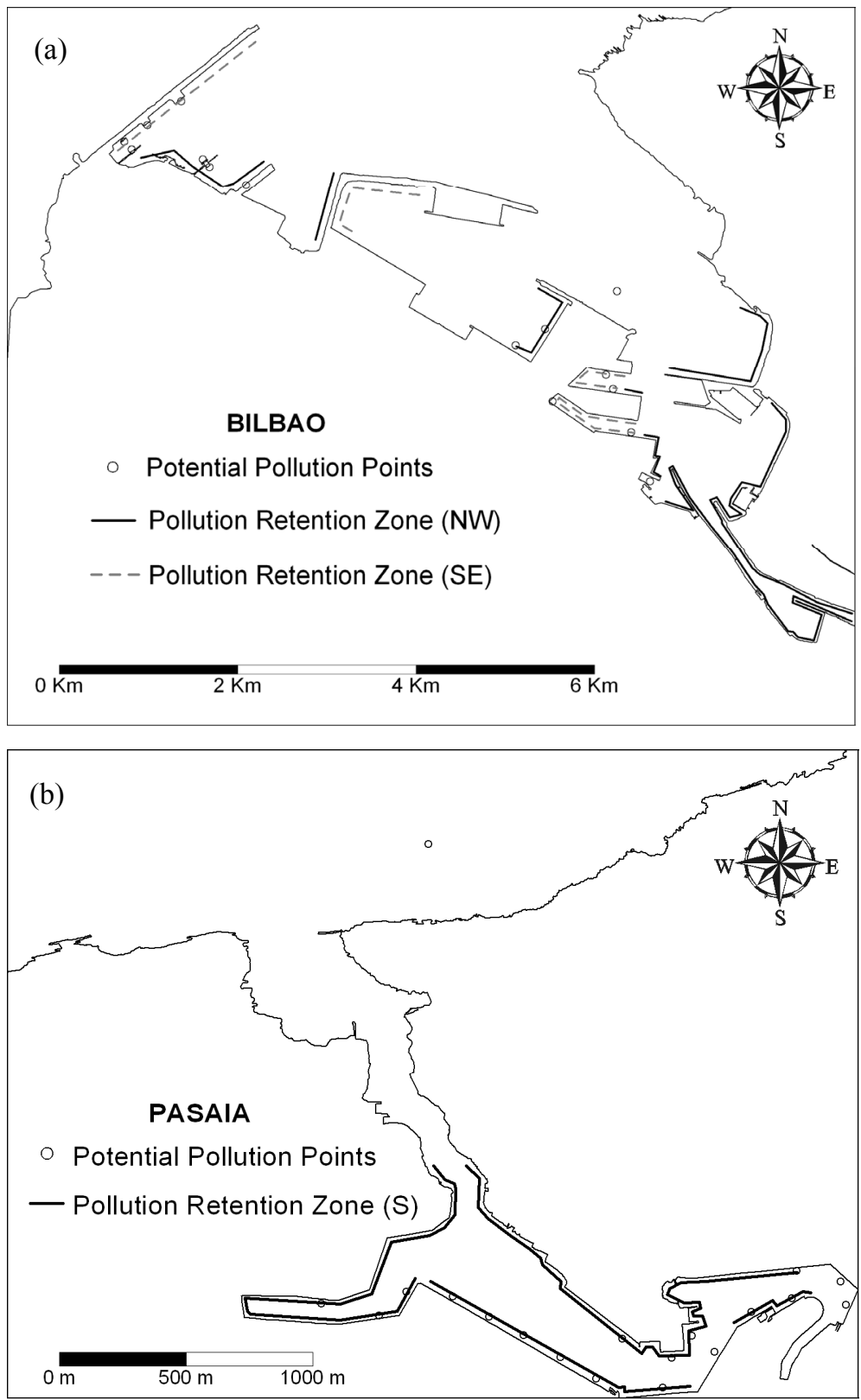

Figure 5: Oil retention zones estimated using prevailing wind conditions: (a) Bilbao harbour (NW and SE winds); and (b) Pasaia harbour (S wind). The location of potential pollution points is also shown. 
harbour. Data acquired from these oceano-meteorological stations seem to be adequate for establishing external surface and open boundary conditions. The extrapolation of the wind patterns registered by these stations to the entire computational harbour domain should be improved by using a high resolution local wind model. Additionally, further research is needed in order to simulate currents induced by breezes in localised areas such as harbours. The preoperational local modelling system described here is being used as a tool for several applications related to harbour management. Some applications, such as environmental risk management of point source pollution and local contingency plans, have been described.

\section{Acknowledgements}

This study has been undertaken with the financial support from different sources: Ministry of Education and Science of the Spanish Government together with the Port Authority of Bilbao (PETRI Program, ref.:PET2006_0111), Port Authority of Pasaia, Department of Industry, Trade and Tourism and Department of Transport and Public Works of the Basque Government (ETORTEK Program, ref.: ITSASEUS and; SAIOTEK Program, ref.: MODELTOX) and AquitaniaEuskadi cooperation (INTERREG Program, ref.: LOREA). We would like to acknowledge Department of Transport and Public Works of the Basque Government and Meteorological and Climatology Direction staff for public provision of oceano-meteorological data.

\section{References}

[1] Fischer, J., Flemming, N., Holt, M. \& R. Rogers, J., 1999. A profile of operational oceanography. EuroGOOS Secretariat.

[2] Ferrer, L., Fontán, A., Mader, J., Chust, G., González, M., Valencia, V., Uriarte, Ad., Collins, M.B., 2009. Low-salinity plumes in the oceanic region of the Basque Country. Continental Shelf Research, 29 (8): 970-984.

[3] Espino, M., 1994. Estabilización de la superficie libre en la solución de Shallow-Water por elementos Finitos. Aplicaciones oceanográficas. Ph. D. thesis, UPC, Barcelona.

[4] González, M., García, M.A., Espino, M., Arcilla, S., 1995. Un modelo numérico en Elementos Finitos para la corriente inducida por la marea. Aplicaciones al Estrecho de Gibraltar. Revista Internacional de Métodos Numéricos para Cálculo y Diseño en Ingeniería, 11 (3): 383-400

[5] Zienkiewicz, O.C., Heinrich, J.C., 1979. A unified treatment of steady state shallow water and two-dimensional Navier-Stokes equations-finite element penalty function approach. Computer Methods in Applied Mechanics and Engineering, 17-18: 673-698.

[6] Fortin, M., Fortin, A., 1985. A generalization of Uzawa's Algorithm for the solution of the Navier-Stokes Equations. Communications in Applied Numerical Methods, 1: 205-208. 
[7] Walters, R.A., 1986. A finite Element Model for tidal and residual circulation. Communications in Applied Numerical Methods, 2: 393-398.

[8] Medina, M., 1974. La mar y el tiempo. Meteorología náutica para aficionados, navegación deportiva y pescadores. Editorial Juventud, 160 pp.

[9] Usabiaga, J.I., Sáenz, J., Valencia, V., Borja, A., 2004. Climate and Meteorology: variability and its influence on the Ocean. In: Borja, A. and Collins, M. (eds.). Oceanography and Marine Environment of the Basque Country, Elsevier Oceanography Series, 70: 75-95, Elsevier, Amsterdam.

[10] Fontán, A., González, M., Wells, N., Collins, M., Mader, J., Ferrer, L., Esnaola, G., Uriarte, Ad., 2009. Tidal and wind-induced circulation within the southeastern limit of the Bay of Biscay: Pasaia Bay, Basque coast. Continental shelf research, 29 (8): 998-1007.

[11] Jirka, G.H., Doneker, R.L., Barnwell, T.O., 1991. CORMIX: A Comprehensive Expert System for Mixing Zone Analysis of Aqueous Pollutant Discharges. Water Science and Technology, 24 (6): 267-274. 